\title{
Effect of timing and female quality on clutch size in the Collared Flycatcher Ficedula albicollis
}

\author{
LÁSZLÓ Z. GARAMSZEGI ${ }^{1,2 *}$, JÁNOS TÖRÖK², LÁSZLÓ TÓTH² and GÁBOR MICHL ${ }^{2}$ \\ 'Department of Biology, University of Antwerp, Universiteitsplein 1, B-2610 Wilrijk, Belgium and ${ }^{2}$ Behavioral \\ Ecology Group, Department of Systematic Zoology and Ecology, Eötvös University, H-1088 Budapest, \\ Puskin u. 3, Hungary
}

Capsule Laying date and female age appear to be related to clutch size.

Aims To test two hypotheses ('date' and 'quality'), which might explain why fewer eggs are laid late in the season.

Methods Four years of data and multivariate analysis were used to test the effects of timing of breeding and female quality reflected by morphological variables and age on clutch size in the Collared Flycatcher Ficedula albicollis. We estimated food supply during parental care by measuring diet composition of nestlings.

Results We distinguished the independent effects of date and age of females on clutch size. The type of prey fed to nestlings was different early and late in the season. Hence food supply during the nestling care period may be a limiting environmental factor that indirectly determines clutch size.

Conclusion Our results are consistent with the predictions of the date hypothesis, but the quality hypothesis was also partially supported. Depending on year effects, $30-50 \%$ of the variance in clutch size may be related to the timing of breeding and an additional $5-10 \%$ may be due to quality (age) differences between early- and late-breeding birds.

In single-brooded species, clutch size declines linearly during the season (Murphy 1986, Stutchbury \& Robertson 1988, Igniatuk \& Clark 1991). A hypothesis to explain the seasonal decline in clutch size (called the date or environment hypothesis) assumes that one or more environmental variables change as the season progresses, and birds respond to these changes (Perrins 1970, Daan et al. 1988, Young 1994). At least two types of environmental effects exist: the environment might limit food resources of the laying females; or the seasonally declining nestling food supply or increasing predation risk may indirectly affect clutch size relative to the time of breeding on an evolutionary scale (Williams 1966, Hussel 1972). According to the second mechanism, late arriving, migratory birds have been selected to lay fewer eggs due to the reduced survival probabilities of their offspring.

The quality (condition) hypothesis states that the seasonal trend may be caused by differences in quality of early- and late-breeding birds (von Haartmann 1971,

*Correspondence author. Email: laszlo.garamszegi@ua.ac.be
Price et al. 1988, Kirkpatrick et al. 1990). Quality may include experience, foraging skills, flying ability, predator avoidance and even the quality of territories.

However, it is unlikely that a single hypothesis exclusively explains the seasonal decline in clutch size or other reproductive traits (Daan \& Tinbergen 1997). For example, in Great Tit Parus major, $87 \%$ of the seasonal decline in lifetime reproductive success is attributed to a timing effect and the remainder to quality (Verhulst et al. 1995).

Recently, experimental manipulations of timing of breeding have been applied to separate the effects of environment and quality of parents and/or their territory (Wiggins et al. 1994, Verhulst et al. 1995, Daan \& Tinbergen 1997). However, manipulation may have affected phenotypic quality of experimental birds leading to an experimental bias. For example in clutch size removal experiments, females are forced to lay a new, extra clutch, which can cause changes in body mass or predator avoidance, or manipulation may have other detrimental effects on condition (Verhulst et al. 1995). 
When correlative data are available, the potential determinants of seasonal decline in clutch size can be investigated using multivariate analysis (Winkler \& Allen 1996). The advantage of this method is that several quality variables can be distinguished and controlled for statistically, each of these potentially determining reproductive success and the onset of breeding. The limitation of this multivariate approach is that the estimation of quality of birds using only certain morphological variables is likely to be incomplete. Thus as a result, we can show that quality plays a role, but we cannot assess its quantitative importance. The unmeasured aspects of quality may be pooled together with other residual factors, to which we ascribe the proportion of the total variance of clutch size not determined by the measured variables.

We examine the possible determinants of seasonal decline in clutch size of the single-brooded Collared Flycatcher Ficedula albicollis, a typical hole-nesting, migratory passerine in central European broad-leaved forests. To test the predictions of the quality and the date hypotheses we applied a multivariate analysis to data collected during 1990-93. In an attempt to find a direct or indirect environmental effect on the seasonally declining clutch size we estimated food supply during parental care.

We predicted a positive correlation between female quality and clutch size from the quality hypothesis. We may expect that this relationship emerges directly or indirectly, as quality can affect clutch size via laying date. When quality is factored out statistically, the effect of timing on clutch size should disappear. By contrast, if date of breeding is the principal determinant of clutch size, we can assume that quality will not be related to clutch size after controlling for timing effects.

\section{METHODS}

\section{Study area and species}

Fieldwork was conducted in a middle-aged oak forest in the Pilis Mountains, Hungary. Altogether, 598 artificial nestboxes were established in 1981 in a 32-ha area. Each year three passerines (Collared Flycatcher, Great Tit, Blue Tit P. caeruleus) occupy about $80 \%$ of the boxes for breeding. We analysed the breeding data of the most common hole-nesting species in our study area, the Collared Flycatcher, collected 1990-93. This species is a single-brooded, mainly monogamous, insectivorous bird.

\section{Data collection}

During the breeding season, all nestboxes were checked twice a week. Nesting females were trapped and measured during the first half of the incubation period between 08:00 and 12:00 hours. Clutch size, clutch initiation date and five morphological variables of females (wing, first primary, tail, bill and tarsus length), age and body mass were recorded. Age and body mass were available from 1992 and 1993 only. The laying date of the first egg was calculated, assuming that one egg was laid per day during the laying period. Bill and tarsus measurements were taken with a dial calliper to the nearest $0.1 \mathrm{~mm}$, while the wing and tail variables were measured with a ruler to the nearest millimetre. A Pesola spring balance was used to measure body mass to the nearest $0.1 \mathrm{~g}$.

In some cases, breeding failure may have occurred in the early stages (such as nest building) before the female was caught. In such a situation, the subsequent breeding attempt detected was treated as the first breeding attempt of the female. It was not possible to exclude such females from our analysis, since the nest desertion history for newly caught females was unknown. However, these cases are probably rare $(<5 \%$, Garamszegi et al. unpubl. data) and females with early breeding failure do not have to replace a complete clutch as in removal experiments. If we were certain that a replacement had occurred for a particular female, we used data for her first clutch, but only if it was completed. Otherwise the given female was excluded from our analysis. The use of replacement breeding attempts should increase the variance in the total sample and hence our analysis will be conservative.

Food samples were taken from nestlings 9-11 days old using neck-collars during three hours. Altogether 575 items were collected from 12 nests. A detailed description of the food collection method can be found in Kluyver (1933) and Török (1981). After collection and preparation in the field, food items were categorized into the main arthropod groups in a laboratory.

\section{Variables and statistical analysis}

Age is a binary variable and was set to zero for females caught in their second calendar year and to one for older females. Laying date was standardized across years as days \pm median laying date, where median laying date for each year is set to zero. To obtain normality and homoscedascity we transformed laying date and morphological variables using log transformation 
before entering them in the statistical analyses. Body mass was corrected for the size of individuals by using residuals from a tarsus minus body mass linear regression $\left(F_{1,362}=13.871, P<0.001\right)$. These residuals were used in the subsequent analyses to reflect female condition. Nesting females were entered into the analysis only once, when they nested in more than one year. In this case, we have randomly chosen a single breeding attempt from the lifetime reproductive performance.

To test for the effects of categorical variables (e.g. age) and continuous predictor variables (morphological variables and laying date) in designs with a single dependent variable (clutch size), we used generalized linear regression models. In each analysis we included year effects as a categorical variable, since there may have been effects of different sample sizes in different years and also a potential variation in seasonal decline in clutch size across years. We built effects to be entered in the models using the main effects of predictor variables. A stepwise analysis based on backward deletion procedure allowed us to simplify most of the models by removing non-significant effects $(P>0.05)$. First, while controlling for year effects, we created a model in which we used clutch size as the dependent variable and laying date as independent variable (laying date model). Second, to check how female quality may explain some of the residual variance on clutch size, we added measures of female attributes to the model and, based on the stepwise procedure, we estimated the most parsimonious combination of independent variables (quality model). Since information on female age and condition were available for two years only, we performed the second analysis separately for the whole dataset and for a two-year subset of data. For the analysis based on the whole dataset we used tarsus, bill, wing, first primary and tail length as independent variables. For the two-year subset of data, we entered into the model morphological variables together with age and condition. During the analyses we assumed that morphological variables and other attributes of females represented a measure of female quality (see also Winkler \& Allen 1996).

To analyse the indirect effects of food supply on seasonal decline in clutch size we compared the diet composition of nestlings between early and late broods. Breeders that laid the first egg before or on the median laying date in a year were considered to be early breeders. Late breeders started breeding after the median laying date. We analysed the taxonomic composition of food provided to nestlings for eight early and for four late nests by comparing the relative frequencies of each arthropod group between early and late nests, and also by applying Mann-Whitney U-test to compare the proportion of Lepidoptera larvae across nests with regard to the relative timing of breeding. We focused on this taxonomic group, because caterpillar larvae are known to be important food for the nestling (Löhrl 1976). All statistical procedures were performed with STATISTICA for Windows (Anon. 1994).

\section{RESULTS}

\section{Effects of laying date and female quality on clutch size}

Clutch size in the Collared Flycatcher showed a strong seasonal decline as the breeding season progressed (Fig. $1)$. Laying date explains one-third of the variance in clutch size while holding year effects constant (Table 1). Female tarsus, bill and wing length were significantly related to clutch size, independent of laying date effects (Table 1). However, these female attributes explained very small additional variance in clutch size.

When we used data for two years to test for the effect of female age and female condition, we also found that the highest proportion of variance in clutch size can be explained by the relative time of breeding (Table 2). However, age effects may also be important since this variable explained an additional $6 \%$ of the variance on the number of eggs laid (Table 2).

\section{Indirect environmental effect: diet composition during nestling care}

There was a significant difference in food composition of nestlings between early and late nests and a significant difference in diet composition between early and late nests $\left(\chi^{2}=74.95, \mathrm{df}=7, P<0.001\right)$. This difference may have been partially caused by the decreasing proportion of Lepidoptera larvae during the season (Mann-Whitney U-test: $z=-2.04 P<0.05 n=$ 12, Fig. 2).

\section{DISCUSSION}

Our results suggest that clutch size was strongly related to timing of breeding, but some attributes of females may also be an important determinant of clutch size. However, only female age explained a considerable amount of variation. The diet composition of nestlings differed between early and late broods, suggesting that 


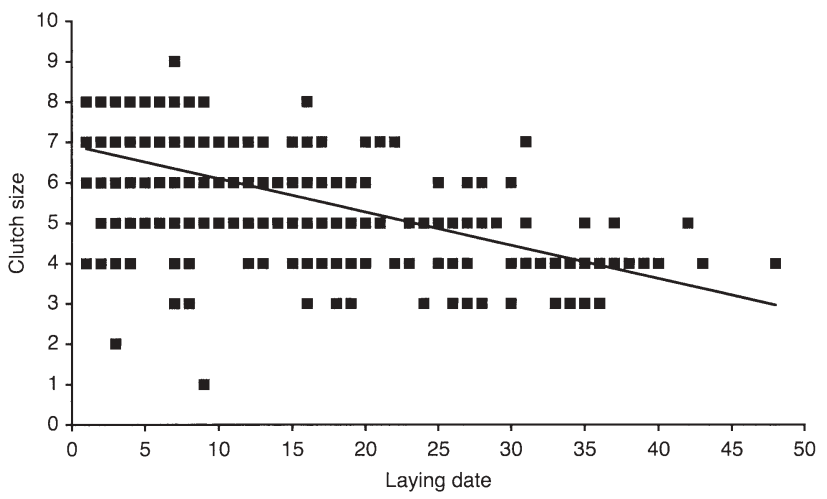

Figure 1. Seasonal decline in clutch size of the Collared Flycatcher in the Pilis Mountains, Hungary in four years. Date ' 1 ' is the day in the season when the first egg appeared in the population. In the analyses, laying date was standardized across years as days \pm median laying date, where median laying date for each year is set to zero.

a seasonal change in food availability may be an indirect selection factor on clutch size. Our results are consistent with the predictions of the date hypothesis, but the quality hypothesis was also partially supported. We conclude that, depending on year effects, 30-50\% of the variance in clutch size may be related to the timing of breeding and an additional $5-10 \%$ may be due to quality (age) differences between early-and late-breeding birds. This finding appears to be similar to that already observed in the Great Tit (Verhulst et al. 1995).

In a northern population of Collared Flycatchers Wiggins et al. (1994) showed that parental and/or territory quality and environmental change during the season affect seasonal variation in reproductive success. In the Pied Flycatcher Ficedula hypoleuca, the north European sibling species of the Collared Flycatcher, timing of breeding is likely to be partly constrained by the capacity of females to lay early, and partly by the time-matching of the nestling period with the peak abundance of available prey (Lundberg \& Alatalo 1992).

\section{Effects of timing}

The advantages of early breeding have been shown in numerous studies. Early clutch initiation has been related to fitness benefits, notably in terms of fledgling survival (Perrins 1970, Norris 1993, Svensson \& Nilsson 1995), territory settlement (Nilsson 1990) moulting (Hemborg 1998), higher food supply (van Balen 1973), social status (Dickinson et al. 1987, Cristol 1995), predation and parasitism pressure (Oppliger et al. 1994, Allander \& Bennett 1995).

However, early breeding has disadvantages as well. Poor feeding conditions (low quality and amount of food supply) may force females to postpone their egglaying mainly in resident species (Perrins 1970, Drent \& Daan 1980, Nilsson 1994). In migrant birds arrival date to the breeding ground constrains the start of egglaying (Sandberg \& Moore 1996).

The date hypothesis on one hand suggests that it is the declining food supply available to laying females that directly causes seasonal decline in clutch size. Highly available food may allow females to maintain

Table 1. Generalized linear models testing the effects of laying date and five morphological variables of females on clutch size of the Collared Flycatcher in four years.

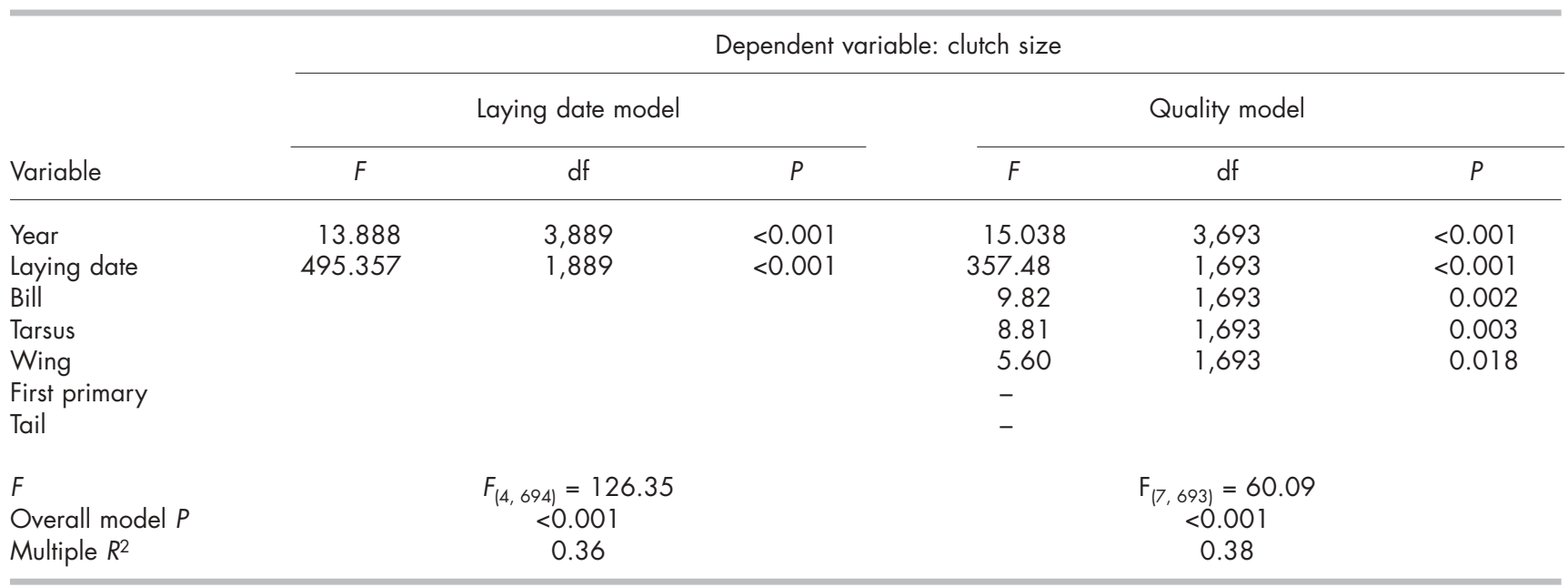

Where no value is recorded, the given variable was not included in the original model; -, the variable was excluded after the stepwise deletion procedure. 
Table 2. Generalized linear models testing the effects of laying date and five morphological variables of females on clutch size of the Collared Flycatcher in two years.

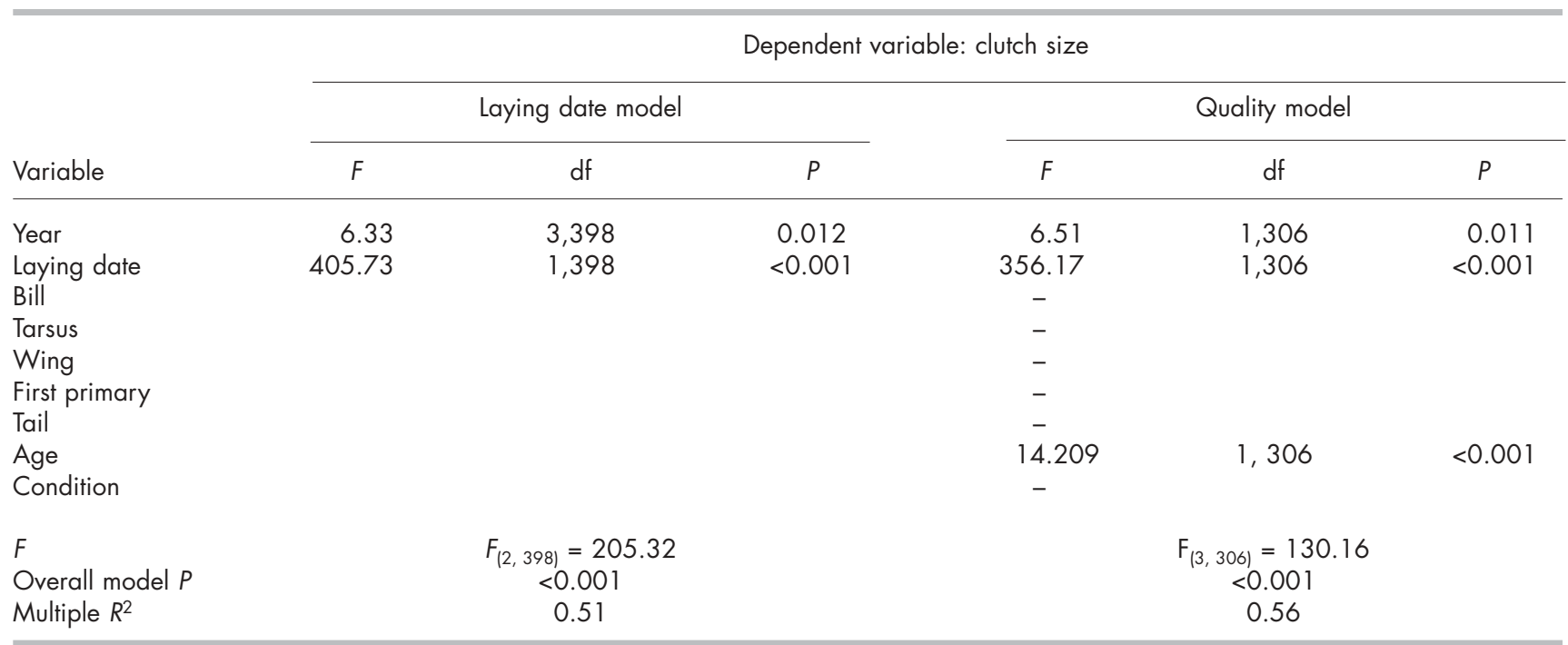

Where no value is recorded, the given variable was not included in the original model; -, the variable was excluded after the stepwise deletion procedure.

the energetic demands of egg-laying, but certain trace elements may also be important for egg formation that can be extracted from the diet. In any case, if clutch size is determined by food supply available to females during the laying period, there should be a close temporal match between the peak abundance of food and the number of breeding attempts. In some tit species, laying date may depend on caterpillar food supply (Perrins 1970). Although caterpillars might be important for egg formation in female tits, in flycatchers other food types (flying insects, spiders) should also be taken into account (Löhrl 1976, Török 1986, Lundberg \& Alatalo 1992; Fig. 2). Hence, the exact role of the temporal distribution of different food items during laying remains to be determined. If laying date of the Collared Flycatcher were synchronized with the abundance of food, it would indicate a direct link between food supply, laying date and clutch size.

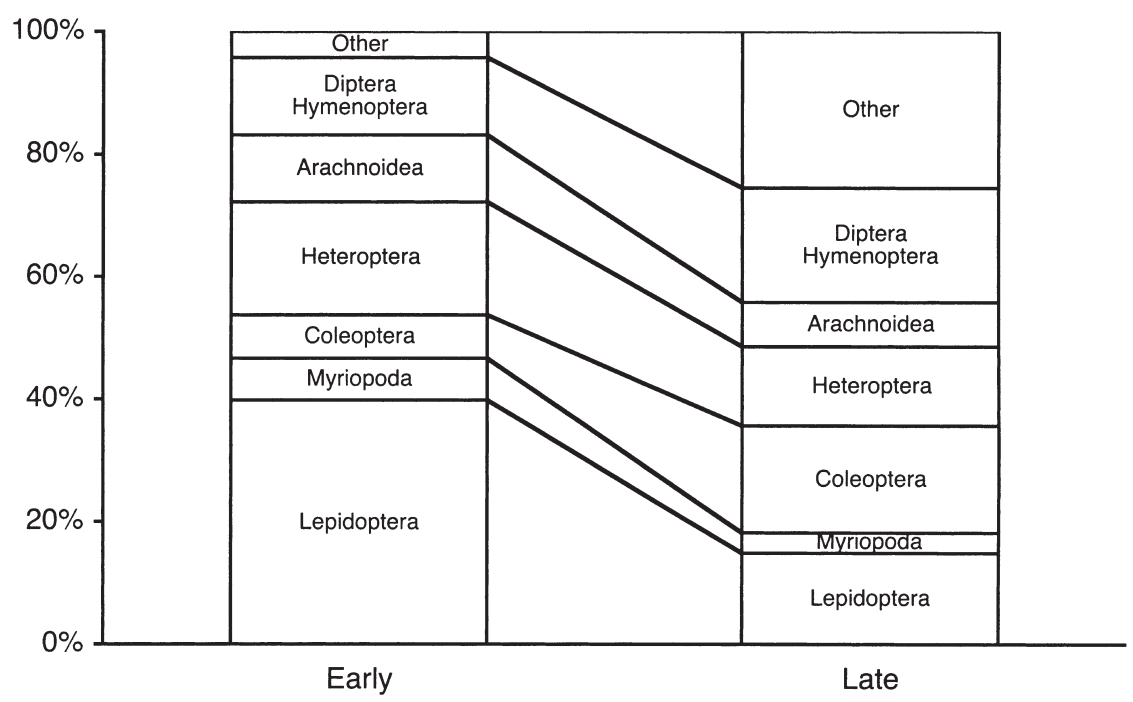

Figure 2. The food composition of nestlings 9-11 days old from eight early and four late broods. Early and late broods were designated relative to the median laying date in the population in the given year; $n=8$ for early and $n=4$ for late broods. 
On the other hand, according to the date hypothesis, temporally changing environmental effects during the nestling period can also drive birds indirectly to optimize their clutch size on a certain laying date. Natural selection will thus favour late-arriving birds that lay smaller clutches, because of the unfavourable environmental effects acting later in the season, e.g. during nestling care. The hypothesis thus assumes that natural selection favours larger clutches when these are laid at a time when hatching on average will coincide with high food availability, and smaller clutches when they are laid at a time when hatching will coincide with lower food availability.

If indirect environmental effects are at work, we predict that early and late clutches are confronted with different environmental circumstances during nestling care that may affect the diet composition of nestlings. Unfortunately, we could not measure the total food supply during nestling care directly, but we were able to detect a difference between the food composition of nestlings in the early and late periods of the season. However, this difference in food composition can be explained by either seasonal changes in food supply and/or the different food preference determined by the demand of nestlings. If these changes are predictable and involve negative fitness consequences for the birds, they can function as selection pressures on seasonal decline in clutch size. At present, it is hard to decide whether the difference in diet composition of nestlings is a result of deteriorating environmental conditions, which drive birds to breed earlier, or related to the actual brood size to which parents adjust the food composition of nestlings.

Perrins $(1970,1996)$ supposed that when the seasonal distribution of food abundance is bell-shaped, females can start to lay if food availability reaches a critical level required for general maintenance. The optimal solution is when the time taken to raise young to independence occurs when food is most abundant. Selection favours those birds that breed early in the season, but only when food has already become plentiful. In these birds we can expect the breeding season to be highly synchronized with the activity and abundance of caterpillars (Perrins 1970, 1996). This laying date adaptation to the fluctuating food supply in tits supports a strong date effect, independent of the condition of breeding birds (Norris 1993, Svensson 1995, Svensson \& Nilsson 1995, Verboven \& Verhulst 1996).

In species like the Pied or Collared Flycatchers timing of breeding is more closely related to arrival than to the food availability before laying (Lundberg \& Alatalo 1992). High latitude migrants are more constrained to begin nesting early, because such birds have shorter time available for reproduction and moult (Sandberg 1996, Sandberg \& Moore 1996). They usually begin their nesting before the food supply becomes plentiful, as they have to rush to finish reproduction before the autumn departure to the wintering area (Slagsvold 1976, Järvinen 1983). Hence, contrary to resident tit species, timing of breeding in Collared Flycatcher is more likely to be constrained by migration than by the timing of peak adult or nestling food supply.

\section{Effects of female quality}

The quality hypothesis predicts that the difference in clutch size of early and late breeding females results from the quality difference of these birds.

As early arrival leads to early breeding (Cristol 1995), we might expect that traits that allow early arrival to the breeding grounds may also allow early breeding and the laying of large clutches. It is known that in some passerine species males arriving early are fitter than later ones (Møller 1994). In our Collared Flycatcher population the average laying date occurs before the vegetation (and thus the food supply) becomes dense. When most birds arrive on the breeding grounds they probably find unfavourable environmental conditions to start breeding. Fat stores accumulated during migration may suggest a mechanism to overcome the unpredictability in foraging circumstances (Sandberg \& Moore 1996). Arriving birds may thus differ in their quality independently of the actual food supply or any environmental circumstance, and this phenomenon could support the quality hypothesis.

We found that female age could explain some variation in clutch size independent of timing effects. Older females having increased breeding experience may be able to bear the costs of raising more chicks to independence compared with younger females commencing their nests on the same day. Late-arriving, older females may perform well in foraging under harsh environmental conditions and in finding a good quality male with superior parental abilities or territory. These advantages can compensate for the negative consequences of late breeding. Hence late-breeding, older females may realize similar reproductive success to that of early breeding young females.

In our multivariate approach, we estimated female quality by using certain morphological variables only. 
As noted in the introduction, this approach involves some limitation because there is no clear evidence for the chosen morphometric characters being good measures of female quality. We assumed that the investigated traits may, at least partly, reflect the quality of individual birds. Based on such incomplete measures, the quantitative role of female quality may be underestimated. Therefore it is possible that unmeasured aspects of female quality can explain some of the residual variance on clutch size.

It is noteworthy that our recent analysis on mating status-dependent survival of females indicated that laying date was significantly repeatable within individuals and across years (Garamszegi et al. 2004). This suggests that laying date may be a female-specific attribute that in turn reflects a role for female quality determining laying date.

\section{Conclusion}

In the Collared Flycatcher both laying date and female age appear to be related to clutch size. Putative measures of female quality had a significant but small influence in determining seasonal decline in clutch size. The proportion of variance explained by date and quality effects was similar to that demonstrated in the Great Tit (Verhulst et al. 1995). Our results show that the diet composition of nestlings was different between early and late broods. This may suggest the existence of temporarily changing environmental factors that shaped the seasonal decline in clutch size on an evolutionary scale.

\section{ACKNOWLEDGEMENT}

We are grateful to A.P. Møller and an anonymous referee for their helpful comments on this paper. We thank S. Verhulst, $\mathrm{J}$-Å. Nilsson and É. Ludvig for their comments on an earlier version of the manuscript. We are indebted to R. Könczey for collecting field data. Partial support was provided by the National Scientific Research Fund (grants: T017058, T022014), the Eötvös Loránd University and Pilis Park Forestry.

\section{REFERENCES}

Allander, K. \& Bennett, G.F. 1995. Retardation of breeding onset in Great Tits (Parus major) by blood parasites. Funct. Ecol. 9: 677-682.

Anon. 1994. STATISTICA for Windows. StatSoft, Inc., Tulsa.

Cristol, D.A. 1995. Early arrival, initiation of nesting, and social status: an experimental study of breeding female red-winged blackbirds. Behav. Ecol. 6: 87-93.

Daan, S. \& Tinbergen, J.N. 1997. Adaptation of life histories. In Krebs, J.R. \& Davies, N.B. (eds) Behavioural Ecology. An Evolutionary Approach: 311-333. Oxford: Blackwell.

Daan, S., Dijkstra, C., Drent, R. \& Meijer, T. 1988. Food supply and the annual timing of avian reproduction. Proc. Int. Ornithol. Congr. 19: 392-407.

Dickinson, T.E., Falls, J.B. \& Kopachena, J. 1987. Effects of female pairing status and timing of breeding on nesting productivity in Western Meadowlarks (Sturnella neglecta). Can. J. Zool. 65: 3093-3101.

Drent, R.H. \& Daan, S. 1980. The prudent parent, energetic adjustments in avian breeding. Ardea 68: 225-252.

Garamszegi, L.Z., Török, J., Michl, G. \& Møller, A.P. 2004. Female survival, lifetime reproductive success and mating status in a passerine bird. Oecologia 138: 48-56.

Hemborg, C. 1998. Reproduction and moult in Pied and Collared Flycatchers (Ficedula hypoleuca and F. albicollis). PhD dissertation. University of Uppsala, Uppsala.

Hussel, D.J.T. 1972. Factors affecting clutch size in Arctic passerines. Ecol. Monogr. 42: 317-364.

Igniatuk, J.B. \& Clark, R.B. 1991. Breeding biology of American crows in Saskatchewan parkland habitat. Can. J. Zool. 69: $168-175$.

Järvinen, A. 1983. Breeding strategies of hole-nesting passerines in northern Lapland. Ann. Zool. Fenn. 20: 129-149.

Kirkpatrick, M., Price, T. \& Arnold, S.J. 1990. The Darwin-Fisher theory of selection in monogamous birds. Evolution 44: 180-193.

Kluyver, H.N. 1933. Bijdrage tot de biologie en de ecologie van den Spreeuw (Sturnus vulgaris vulgaris L.) gedurende zijn voortplantingstijd. PhD dissertation. University of Wageningen, Wageningen.

Löhrl, H. 1976. Studies of less familiar birds. 179. Collared Flycatcher. Br. Birds 69: 20-26.

Lundberg, A. \& Alatalo, R.V. 1992. The Pied Flycatcher. T. \& A.D. Poyser, London.

Møller, A.P. 1994. Phenotype-dependent arrival time and its consequences in a migratory bird. Behav. Ecol. Sociobiol. 35: 115-122.

Murphy, M.T. 1986. Temporal components of reproductive variability in Eastern Kingbirds (Tyrannus tyrannus). Ecology 67: 1483-1492.

Nilsson, J-Å. 1990. Establishment success of experimentally delayed juvenile Marsh Tit Parus palustris. Ethology 85: 73-79.

Nilsson, J-Å. 1994. Energetic bottle-neck during breeding and the reproductive cost of being too early. J. Anim. Ecol. 63: 200-208.

Norris, K. 1993. Seasonal variation in the reproductive success of Blue Tits: an experimental study. J. Anim. Ecol. 62: 287-294.

Oppliger, A., Richner, H. \& Christe, P. 1994. Effect of an ectoparasite on lay date, nest-site choice, desertion, and hatching success in the Great Tit (Parus major). Behav. Ecol. 5: 130-134.

Perrins, C.M. 1970. The timing of birds' breeding seasons. Ibis 112 : 242-255.

Perrins, C.M. 1996. Eggs, egg formation and timing of breeding. Ibis 138: 2-15.

Price, T.M., Kirkpatrick, M. \& Arnold, S.J. 1988. Directional selection and the evolution of breeding date in birds. Science 240: 98-99.

Sandberg, R. 1996. Fat reserves of migratory passerines on arrival at the breeding grounds in Swedish Lapland. Ibis 138: 14-24.

Sandberg, R. \& Moore, F.R. 1996. Fat stores and arrival on the breeding grounds: reproductive consequences for passerine migrants. Oikos 77: 77-81.

Slagsvold, T. 1976. Annual and geomorphological variation in the time of breeding in the Great Tit Parus major and the Pied Flycatcher 
Ficedula hypoleuca in relation to environmental phenology and spring temperature. Ornis Scand. 7: 27-45.

Stutchbury, B.J. \& Robertson, R.J. 1988. Within-season and agerelated patterns of reproductive performance in female Tree Swallows (Tachycineta bicolor). Can. J. Zool. 66: 827-834.

Svensson, E. 1995. Avian reproductive timing: when should parents be prudent? Anim. Behav. 49: 1569-1575.

Svensson, E. \& Nilsson, J-Å. 1995. Food supply, territory quality, and reproductive timing in the Blue Tit (Parus caeruleus). Ecology 76: 1804-1812.

Török, J. 1981. Food composition of nesting Blackbirds in an oak forest bordering on an orchard. Opus. Zool. (Budap.) 17: $145-156$.

Török, J. 1986. Food separation in three hole nester bird species during the breeding season. Ardea 74: 129-136.

van Balen, J.H. 1973. A comparative study of the breeding ecology of the Great Tit Parus major in different habitats. Ardea 61: 1-93.

Verboven, N. \& Verhulst, S. 1996. Seasonal variation in the inci- dence of double broods: the date hypothesis fits better than the quality hypothesis. J. Anim. Ecol. 65: 264-273.

Verhulst, S., van Balen, J.H. \& Tinbergen, J.M. 1995. Seasonal decline in reproductive success of the Great Tit: variation in time or quality? Ecology 76: 2392-2403.

von Haartmann, L. 1971. Population dynamics. In Farner, D.S. \& King, J.R. (eds) Avian Biology, Vol. 1: 391-459. Academic Press, New York.

Wiggins, D.A., Pärt, T. \& Gustafsson, L. 1994. Seasonal decline in Collared Flycatcher Ficedula albicollis reproductive success: an experimental approach. Oikos 70: 359-364.

Williams, G.C. 1966. Natural selection, the cost of reproduction and the refinement of Lack's principle. Am. Nat. 100: 687-692.

Winkler, D.W. \& Allen, P.E. 1996. The seasonal decline in Tree Swallow clutch size: physiological constraint or strategic adjustment? Ecology 77: 922-932.

Young, B.E. 1994. Geographic and seasonal patterns of clutch size variation in House Wrens. Auk 111 : 545-555.

(MS received 10 March 2003; revised MS accepted 3 December 2003) 